\title{
The Study of Cooling Process on Runout Table by Simulation Method
}

\author{
Anan Suebsomran' ${ }^{1}$ and Suthep Butdee ${ }^{2}$ \\ ${ }^{1}$ Department of Teacher Training in Mechanical Engineering, King Mongkut's University of Technology North Bangkok, \\ 1518 Pracharat 1 Road, Wongsawang, Bangsue, Bangkok 10800, Thailand \\ ${ }^{2}$ Department of Production Engineering, King Mongkut's University of Technology North Bangkok, 1518 Pracharat 1 Road, \\ Wongsawang, Bangsue, Bangkok 10800, Thailand
}

Correspondence should be addressed to Anan Suebsomran; asr@kmutnb.ac.th

Received 29 May 2013; Accepted 2 September 2013

Academic Editors: G. Dobmann and L. Jelemensky

Copyright (C) 2013 A. Suebsomran and S. Butdee. This is an open access article distributed under the Creative Commons Attribution License, which permits unrestricted use, distribution, and reproduction in any medium, provided the original work is properly cited.

\begin{abstract}
This research aims to achieving the effective cooling parameter on the runout table (ROT) of strip steel in hot rolling process. The 2-dimensional transient heat conduction is developed including the external force convection and heat source due to translational motion. The material property, boundary, and initial condition are defined and bounded to model geometry. The strip velocity, cooling water temperature, and external fluid velocity are chosen for the influent parameters during cooling process at ROT. To find the optimality of cooling operating requirement, simulation study is conducted throughout this research. To reach the objective of optimal cooling consumption at ROT, temperature distribution in the strip steel during cooling governs by the form of heat transfer equation. To solve 2-dimensional transient heat conduction by numerical methods, the backward difference formula (BDF) applies to discretization of partial differentiation equation (PDE). The parallel sparse direct linear solver (PARDISO) and conjugate gradients method are comparatively applied to computation in linear algebraic equation. The simulation studies are divided into 12 case studies with three variations subjected to cooling conditions at ROT. From simulation results, the range of such three variations can be identified in relation to economic cooling system and desired quality of products.
\end{abstract}

\section{Introduction}

Recently, advanced material processing technology must have become suitable for low cost of production, high productivity, and better quality of product. Manufacturing process of steel making is a long distance process. Slap products are passed to several machines to gain the desired size of product such as roughing mill machine, finishing rolling mill. After finishing rolling stand, the steel strip type is defined at this stage. Mechanical and physical properties of steel strip are controlled for the desired product quality. Temperature is one of the main parameters to control the product properties. After finishing stand process, the next process of the strip steel will arrive to runout table (ROT) as depicted in Figure 1. Runout table (ROT) employs to cool down the temperature approximately from $800-950^{\circ} \mathrm{C}$ at the entrance to the ROT to $450-600^{\circ} \mathrm{C}$ at exit from the ROT. If temperature is cooled down linearly as described, then phase transformation of strip steel will change from austenite to ferrite of metallurgy structure. The water wall uses for cooling the strip temperature by nozzle jet in both bottom and top of strip surface. To save the water consumption in cooling process at ROT, the optimal cooling of control parameters during cooling is required to conduct this research. In this study, three variations such as strip velocity, external fluid velocity, and cooling water temperature subjected to cooling conditions at ROT are used for studying the effective cooling variables. Problem of cooling at ROT process for the optimal cooling variables is derived for operational method in practical manner.

This research is an extension of the previous research [1]. The extension of research is to study the influence of two kinds of linear algebra computation influent to the temperature of strip steel. Many researches attempt to analyse the cooling system at runout table. Reference [2] implemented the online runout table model in a hot steel mill. Coiling 


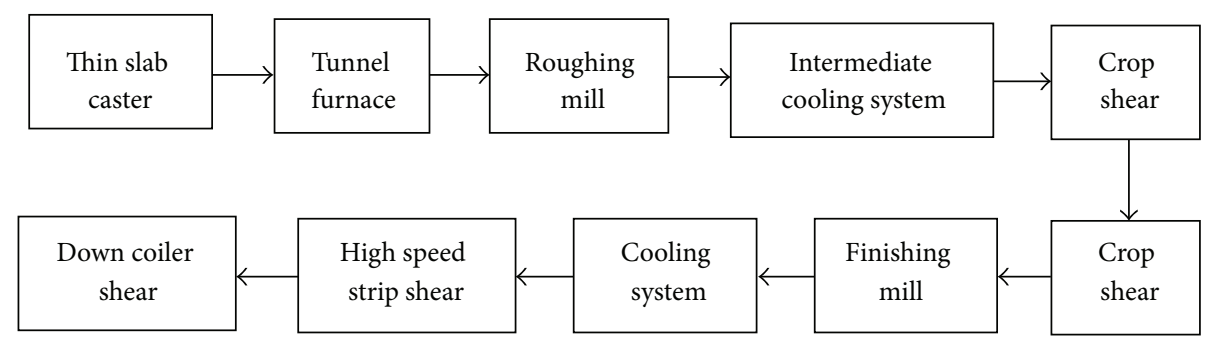

FIGURE 1: Layout of hot rolling process of strip steel production.

temperature is the main parameter to perform the online cooling at runout table such as using the inversion temperature control technique. Prediction of coiling temperature is implemented by online runout table model using PLC to control the condition of cooling in each segment with the appropriate cooling rates. This research developed only $1 \mathrm{D}$ conduction transient heat transfer and lacked consideration of strip velocity. Thus, prediction of temperature by online runout table model would be not exactly accurate in cooling rate control. Reference [3] also predicted the thermal and metallurgical behavior by using finite element model at runout table. Finite element coupled analysis of the thermal and metallurgical behavior of strip occurring at runout table for hot strip rolling process. Simulation result is compared with the thermal measurements in validation. The simulation model revealed that the effect of diverse process parameters is demonstrated in this research. And the prediction of temperature and phase transform at runout table is also described by $[4,5]$.

The mathematical model [4] is based on finite element method and the Scheil additive rule to prediction thermal and phase transformation. The mathematical and simulation model are not conflicted in the present work. The mathematical model is described in rectangular coordinate, but simulation results show the cylindrical coordinate. Reference [5] proposed the model of heat transfer equation of moving strip, but this proposed model studied only heat transfer in the steady state condition. From simulation result, when we increase the strip speed, the slop of cooling curve will decrease. Then, the starting point of ferrite transformation moves to the end of runout table position. This research demonstrated that the effect parameters of thermal and phase transform are affected by strip speed and initial gain austenite size of microstructure of metal changed to ferrite microstructure for a low carbon steel. Reference [6] also presented the modeling of temperature history and phase transforms during cooling of steel by using the finite element model. The simulation in prediction of temperature and phase transformation is compared to the experiment methods to validate the proposed prediction model. The model of deformation, temperature, and phase transformation behavior of strip steel on runout table is presented in the numerical model to simulate the followed behavior. The thermal model is formulated by using finite element and heat transfer coefficient of strip from actual mill data. The additional model included the deformation behavior into developed model proposed by [7]. Reference [8] presented the prediction accuracy of strip temperature due to the effect of phase transformation latent heat in laminar cooling. The model was used to calculate the strip temperature and volume fraction of steel phase during cooling at runout table into different situations by regarding and disregarding phase transform latent heat. Comparison of prediction and experiment leaded to the errors in temperature prediction. The different steel grades showed that that the higher the carbon contents of steel, the higher the error of disregarding phase transformation latent heat. Not only the essential study on prediction temperature and phase transformation, but also [9] extended to describe the calculation of thermal stress affecting strip flatness change during runout table cooling in hot steel strip rolling in the effect of flatness of strip. The finite element was used to analyze the thermal stress during cooling. The commercial finite element software ABAQUS is used to analyse and calculate thermal behavior. References $[10,11]$ studied the cooling system. Experiment is set up to study the effect of cooling parameters at runout table. Thus control design of cooling system at runout table planned to implement to an industrial plant. From the literature, we found that most of researches are aimed to study the thermal and metallurgical behavior of strip during cooling at runout table. Method of prediction of temperature and phase transformation is mostly applied for the design of cooling process. To reach the desired product quality, temperature must be controlled according to the appropriation of the mechanical, physical, and metallurgy property. To design the cooling system at runout table, the heat transfer must be modeled in strip steel. An amount of heat flux in the strip steel must be evaluated in each condition that occurs on the actual industrial operation conditions. In this research, we have the goal of finding the effect of cooling parameters of strip steel at ROT.

\section{Mathematical Model}

2.1. Conduction Heat Transfer Model. Mathematical model of heat conduction in strip at runout table in rectangular coordinate can be formulated to describe the thermal behavior. The physical system is modeled in two-dimensional heat transfer equation of moving strip. The transient analysis of heat transfer of moving strip can be described by (1) as explained by [5]:

$$
\frac{\partial}{\partial x}\left(k \frac{\partial T}{\partial x}\right)+\frac{\partial}{\partial z}\left(k \frac{\partial T}{\partial z}\right)+\dot{q}=\rho c u_{i} \frac{\partial T}{\partial x}+\rho c \frac{\partial T}{\partial t},
$$


where $\rho$ is the density, $c$ is the temperature dependent specific heat, and $k$ is the temperature dependent thermal conductivity of the material. $u_{i}$ is strip velocity. $T$ and $t$ are temperature and time, respectively; $\dot{q}$ is the heat generation term representing the internal heat source released due to phase transformation.

2.2. Boundary and Initial Conditions. The differential equation needs to be solved by numerical methods. The heat conduction occurs on the slap surface. The convection heat transfer applied the force convection and natural convection using water and air, respectively. At runout table, conduction of heat transfer in strip surface can be set to boundary conditions by (2):

$$
-k \frac{\partial T}{\partial z}=h_{w}\left(T-T_{w}\right)
$$

where $z$ is the normal direction of strip's surface. $h_{w}$ is the coefficient of convection heat transfer. $T_{w}$ is the temperature of water. $T$ is the strip temperature.

Boundary condition at inlet region is

$$
T(0, z)=T(z)
$$

Boundary condition at outlet region is

$$
\left.\frac{\partial T}{\partial x}\right|_{x=L}=0
$$

Initial condition is set by (5) as

$$
T(x, z, t=0)=T_{0,0},
$$

where $T(z)$ is the temperature distribution in $z$ direction. $L$ is the runout table length in $x$ direction.

\section{Numerical Solution}

3.1. Discretization Methods. Backward difference formula (BDF) is applied to estimate the first and second order derivative equation as shown in (6). Thus, discretization can be evaluated using the continuous time derivation:

$$
\begin{gathered}
f^{\prime}\left(x_{i}\right) \cong \frac{f\left(x_{i}\right)-f\left(x_{i-1}\right)}{h}+O(h), \\
f^{\prime \prime}\left(x_{i}\right) \cong \frac{f\left(x_{i}\right)-2 f\left(x_{i-1}\right)+f\left(x_{i-2}\right)}{h^{2}}+O(h) .
\end{gathered}
$$

Two-dimensional heat transfer equation in (1) can be approximated by a simple backward difference formula (BDF).
In this model, partial differential equation is approximated with the proper time stepping interval in (7):

$$
\begin{gathered}
\frac{\partial^{2} T}{\partial x} \cong \frac{T_{i, j}-2 T_{i-1, j}+T_{i-2, j}}{\Delta x^{2}}+O(\Delta x), \\
\frac{\partial^{2} T}{\partial z} \cong \frac{T_{i, j}-2 T_{i, j-1}+T_{i, j-2}}{\Delta z^{2}}+O(\Delta z), \\
\frac{\partial T}{\partial x} \cong \frac{T_{i, j}-T_{i-1, j}}{\Delta x}+O(\Delta x), \\
\frac{\partial T}{\partial t} \cong \frac{T_{i, j}-T_{i-1, j}}{\Delta t}+O(\Delta t) .
\end{gathered}
$$

Time-dependent problem is solved by using implicit time stepping scheme. The step time $(\Delta t)$ must be small enough with uniform grid in spatial rectangular domain, and it can be calculated for uniform conductivity by (8) for equal space grid in spatial coordinate in reference $x, z$ coordinates in $[12,13]$ :

$$
\Delta t<\frac{\rho c(\Delta x)^{2}}{2 k} .
$$

The final discretization approximated by using implicit time stepping method can be expressed by (9) by neglecting the source term $\dot{q}$; then,

$$
\begin{array}{r}
\frac{T_{i, j}-2 T_{i-1, j}+T_{i-2, j}}{\Delta x^{2}}+\frac{T_{i, j}-2 T_{i, j-1}+T_{i, j-2}}{\Delta z^{2}} \\
=\frac{\rho c}{k} u \frac{T_{i, j}-T_{i-1, j}}{\Delta x}+\frac{\rho c}{k} \frac{T_{i, j}-T_{i-1, j}}{\Delta t} .
\end{array}
$$

The update time derivative of model can be calculated to the specification of time stepping interval. Based on implicit time stepping method, the iterative solution can be formulated by using the finite difference methods. Since $u_{i}$ is the strip velocity with unidirectional translational motion, the PDE for heat transfer referred in (1) can be solved by implicit finite difference equation by using the upwind scheme which follows to discretization in (10).

Forward time derivative for $\partial T / \partial t$ is used, and the backward derivative for $\partial T / \partial x, \partial^{2} T / \partial x^{2}$ and $\partial^{2} T / \partial z^{2}$ is used. This results in upwind scheme:

$$
\begin{aligned}
\frac{\rho c}{k} \frac{T_{i, j}^{n+1}-T_{i, j}^{n}}{\tau}= & \frac{T_{i, j}^{n}-2 T_{i-1, j}^{n}+T_{i-2, j}^{n}}{\Delta x^{2}} \\
& +\frac{T_{i, j}^{n}-2 T_{i, j-1}^{n}+T_{i, j-2}^{n}}{\Delta z^{2}}-\frac{\rho c u_{i}}{k} \frac{T_{i, j}^{n}-T_{i-1, j}^{n}}{\Delta x},
\end{aligned}
$$

$$
\begin{aligned}
T_{i, j}^{n+1}-T_{i, j}^{n}= & \frac{k \tau}{\rho c \Delta x^{2}}\left(T_{i, j}^{n}-2 T_{i-1, j}^{n}+T_{i-2, j}^{n}\right) \\
& +\frac{k \tau}{\rho c \Delta z^{2}}\left(T_{i, j}^{n}-2 T_{i, j-1}^{n}+T_{i, j-2}^{n}\right) \\
& -\frac{k \tau}{\rho c} \frac{\rho c u_{i}}{k \Delta x}\left(T_{i, j}^{n}-T_{i-1, j}^{n}\right) .
\end{aligned}
$$




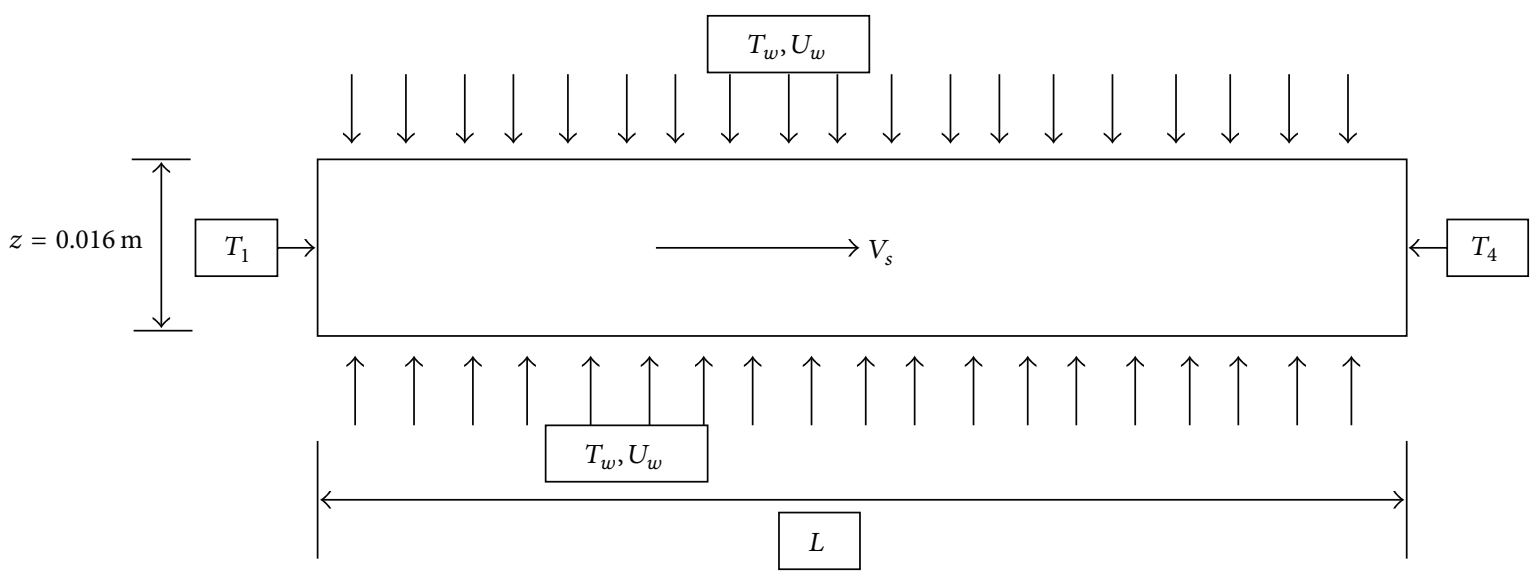

FIgURE 2: Boundary and condition setting.

The formulation of each numerical method is shown below. $\Delta x$ and $\Delta z$ are the space between two space grid points or the space step size, and $\tau$ is used to represent $\Delta t$, the time step. The above equation (10) is modified by evaluating the space backward derivative at time step $n+1$ instead of at time step $n$; this results in (12)

$$
\begin{array}{r}
T_{i, j}^{n+1}-\frac{k \tau}{\rho c \Delta x^{2}}\left(T_{i, j}^{n}-2 T_{i-1, j}^{n}+T_{i-2, j}^{n}\right) \\
-\frac{k \tau}{\rho c \Delta z^{2}}\left(T_{i, j}^{n}-2 T_{i, j-1}^{n}+T_{i, j-2}^{n}\right) \\
+\frac{k \tau}{\rho c} \frac{\rho c u_{i}}{k \Delta x}\left(T_{i, j}^{n}-T_{i-1}^{n}\right)=T_{i, j}^{n} .
\end{array}
$$

By rearranging that discretization equation, we finally get the final result in (13):

$$
\begin{aligned}
T_{i, j}^{n}= & T_{i, j}^{n+1}-\frac{\tau k}{\rho c \Delta x^{2}} T_{i, j}^{n+1}-\frac{\tau k}{\rho c \Delta z^{2}} T_{i, j}^{n+1}+\frac{\tau u_{i}}{\Delta x} T_{i, j}^{n+1} \\
& +\frac{\tau k}{\rho c \Delta x^{2}} 2 T_{i-1, j}^{n+1}-\frac{\tau u_{i}}{\Delta x} T_{i-1, j}^{n+1} \\
& +\frac{\tau k}{\rho c \Delta z^{2}} 2 T_{i, j-1}^{n+1}-\frac{\tau k}{\rho c \Delta x^{2}} T_{i-2, j}^{n+1}-\frac{\tau k}{\rho c \Delta z^{2}} T_{i, j-2}^{n+1}
\end{aligned}
$$

Rearranging new form, it can be represented by (14):

$$
\begin{aligned}
& a_{p} T_{i, j}^{n+1}+a_{w-1} T_{i-1, j}^{n+1}+a_{w-2} T_{i-2, j}^{n+1}+a_{s-1} T_{i, j-1}^{n+1} \\
& \quad+a_{s-2} T_{i, j-2}^{n+1}=T_{i, j}^{n},
\end{aligned}
$$

where

$$
\begin{gathered}
a_{p}=1-\frac{\tau \alpha}{\Delta x^{2}}-\frac{\tau \alpha}{\Delta z^{2}}+\frac{\tau u_{i}}{\Delta x}, \\
a_{w-1}=\frac{2 \tau \alpha}{\Delta x^{2}}-\frac{u_{j} \tau}{\Delta x} \quad a_{w-2}=-\frac{\tau \alpha}{\Delta x^{2}}, \\
a_{s-1}=\frac{2 \tau \alpha}{\Delta z^{2}} \quad a_{s-2}=-\frac{\tau \alpha}{\Delta z^{2}},
\end{gathered}
$$

where $\alpha=k / \rho c$ is the constant of material; this will show stable if $\tau u_{i} / \Delta x \leq 1, \tau \alpha / \Delta x^{2} \leq 1$, and $\tau \alpha / \Delta z^{2} \leq 1$. Writing it in matrix form it results in (16):

$$
\begin{gathered}
{\left[\begin{array}{cccccccc}
a_{p} & a_{s-1} & a_{s-2} & 0 & 0 & \cdots & 0 & 0 \\
a_{w-1} & a_{p} & a_{s-1} & a_{s-2} & 0 & \cdots & 0 & 0 \\
a_{w-2} & a_{w-1} & a_{p} & a_{s-1} & a_{s-2} & \cdots & 0 & 0 \\
0 & a_{w-2} & a_{w-1} & a_{p} & a_{s-1} & a_{s-2} & 0 & 0 \\
0 & 0 & a_{w-2} & a_{w-1} & a_{p} & a_{s-1} & 0 & 0 \\
0 & 0 & 0 & a_{w-2} & a_{w-1} & a_{p} & \cdots & 0 \\
\vdots & & & & & & & \\
0 & 0 & 0 & 0 & 0 & a_{p}
\end{array}\right]} \\
\\
\times\left[\begin{array}{c}
T_{0,0}^{n+1} \\
T_{1,1}^{n+1} \\
T_{2,2}^{n+1} \\
T_{3,3}^{n+1} \\
T_{4,4}^{n+1} \\
\vdots \\
T_{N-1, M-1}^{n+1} \\
T_{N-2, M-2}^{n+1}
\end{array}\right]=\left[\begin{array}{c}
T_{0,0}^{n} \\
T_{1,1}^{n} \\
T_{2,2}^{n} \\
T_{3,3}^{n} \\
T_{4,4}^{n} \\
\vdots \\
T_{N-1, M-1}^{n} \\
T_{N-2, M-2}^{n}
\end{array}\right],
\end{gathered}
$$

where $N$ is the number of space grid points. The above equation (16) is written in linear algebraic equation form as expressed in (17):

$$
\mathbf{A x}=\mathbf{b}
$$

To determining $\mathbf{x}$, which represents the solution at time step $n+1$ or at time $t=(n+1) \tau$. $\mathbf{b}$ represents the current solution at time step $n$, and $\mathbf{A}$ is the coefficients of matrix.

\section{Simulation Model}

In simulation, we set boundary and condition of $2 \mathrm{D}$ heat transfer model as illustrated in Figure 2. Details are listed as follows:

(i) $2 \mathrm{D}$ heat conduction transfer in transient analysis, 
TABLE 1: Case of simulation studied on changing three variables.

\begin{tabular}{|c|c|c|c|}
\hline Case study & $\begin{array}{l}\text { Strip velocity }\left(V_{s}\right) \\
(\mathrm{m} / \mathrm{s})\end{array}$ & $\begin{array}{l}\text { Fluid velocity }\left(U_{w}\right) \\
\qquad(\mathrm{m} / \mathrm{s})\end{array}$ & $\begin{array}{c}\text { Cooling water } \\
\text { temperature }\left(T_{f}\right) \\
\left({ }^{\circ} \mathrm{K}\right)\end{array}$ \\
\hline 1 & $V_{s}=10$ & $U_{w}=20$ & $T_{f}=288$ \\
\hline 2 & $V_{s}=10$ & $U_{w}=20$ & $T_{f}=293$ \\
\hline 3 & $V_{s}=10$ & $U_{w}=30$ & $T_{f}=288$ \\
\hline 4 & $V_{s}=10$ & $U_{w}=30$ & $T_{f}=293$ \\
\hline 5 & $V_{s}=7$ & $U_{w}=20$ & $T_{f}=288$ \\
\hline 6 & $V_{s}=7$ & $U_{w}=20$ & $T_{f}=293$ \\
\hline 7 & $V_{s}=7$ & $U_{w}=30$ & $T_{f}=288$ \\
\hline 8 & $V_{s}=7$ & $U_{w}=30$ & $T_{f}=293$ \\
\hline 9 & $V_{s}=0$ & $U_{w}=20$ & $T_{f}=288$ \\
\hline 10 & $V_{s}=0$ & $U_{w}=20$ & $T_{f}=293$ \\
\hline 11 & $V_{s}=0$ & $U_{w}=30$ & $T_{f}=288$ \\
\hline 12 & $V_{s}=0$ & $U_{w}=30$ & $T_{f}=293$ \\
\hline
\end{tabular}

TABLE 2: Output of surface temperature at ROT.

\begin{tabular}{|c|c|c|c|c|c|}
\hline Case study no. & $\begin{array}{c}\text { Entrance ROT } \\
\text { temperature } \\
\left({ }^{\circ} \mathrm{K}\right) \\
\end{array}$ & $\begin{array}{c}\text { Reference at exit ROT } \\
\text { temperature } \\
\left({ }^{\circ} \mathrm{K}\right)\end{array}$ & $\begin{array}{c}\text { Actual surface } \\
\text { temperature } \\
\left({ }^{\circ} \mathrm{K}\right) \\
\end{array}$ & True error & $\begin{array}{l}\text { Percent relative error } \\
\qquad\left(\varepsilon_{t}\right)\end{array}$ \\
\hline 1 & 1148 & 793 & 754.31 & 38.69 & 0.048789407 \\
\hline 2 & 1148 & 793 & 720.7 & 72.3 & 0.091172762 \\
\hline 3 & 1148 & 793 & 458.85 & 334.15 & 0.421374527 \\
\hline 4 & 1148 & 793 & 455.25 & 337.75 & 0.42591425 \\
\hline 5 & 1148 & 793 & 679.96 & 113.04 & 0.142547289 \\
\hline 6 & 1148 & 793 & 455.25 & 337.75 & 0.42591425 \\
\hline 7 & 1148 & 793 & 679.96 & 113.04 & 0.142547289 \\
\hline 8 & 1148 & 793 & 503.6 & 289.4 & 0.364943253 \\
\hline 9 & 1148 & 793 & 441.85 & 351.15 & 0.442812106 \\
\hline 10 & 1148 & 793 & 440.4 & 352.6 & 0.444640605 \\
\hline 11 & 1148 & 793 & 375.32 & 417.68 & 0.526708701 \\
\hline 12 & 1148 & 793 & 378.7 & 414.3 & 0.522446406 \\
\hline
\end{tabular}

(ii) strip dimension $0.016 \times 47 \mathrm{~m}$,

(iii) steel type AISI 4340,

(iv) convective cooling by water at total plate length $47 \mathrm{~m}$ with average heat transfer coefficient $\left(h_{w}\right)$ by external force convection,

(v) initial value for strip temperature $1148 \mathrm{~K}$,

(vi) $T_{1}=1148 \mathrm{~K}$,

(vii) $T_{4}=793 \mathrm{~K}$,

(viii) no heat source $Q$,

(ix) no heat flux generation at all boundaries,

(x) strip velocity: $V_{s}(\mathrm{~m} / \mathrm{s})$,

(xi) external fluid velocity: $U_{w}(\mathrm{~m} / \mathrm{s})$,

(xii) temperature of cooling water: $T_{f}\left({ }^{\circ} \mathrm{K}\right)$.

This research utilized the Comsol Multiphysics software to build the model and solve with the numerical methods as in
$[14,15]$. The developed model set the configuration as shown in Figure 2. In this study, the changed variables for simulation are included by three parameters such as strip velocity $\left(V_{s}\right)$, external fluid velocity $\left(U_{w}\right)$ and temperature of cooling water $\left(T_{f}\right)$ respectively. These affect strip temperature control at entrance and exit ROT, and it can show in Table 1 for case study in simulation.

At runout table of cooling process of strip steel, we specify the strip temperature at entrance ROT and exist ROT indicated in Table 2. To keep the desired product quality and requirement, cooling process requires to control the strip temperature after exist ROT as shown in Table 2. The aim of simulation study verifies the minimum strip temperature error compared to the reference strip temperature at exit ROT as shown in Table 2. Thus, percent true relative error is useful for computation by (18):

$$
\varepsilon_{t}=\frac{\text { True error }}{\text { True value }} \times 100 .
$$




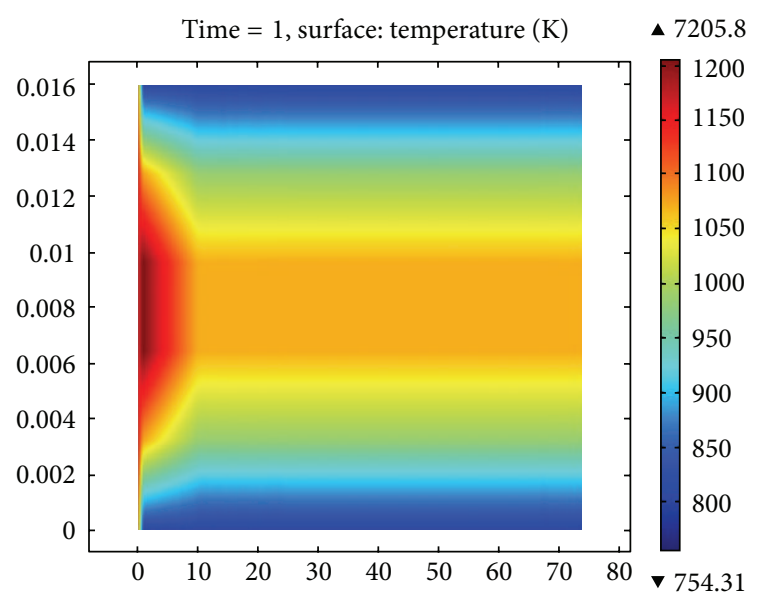

FIGURE 3: Temperature of strip using the parallel sparse direct linear solver (PARDISO).

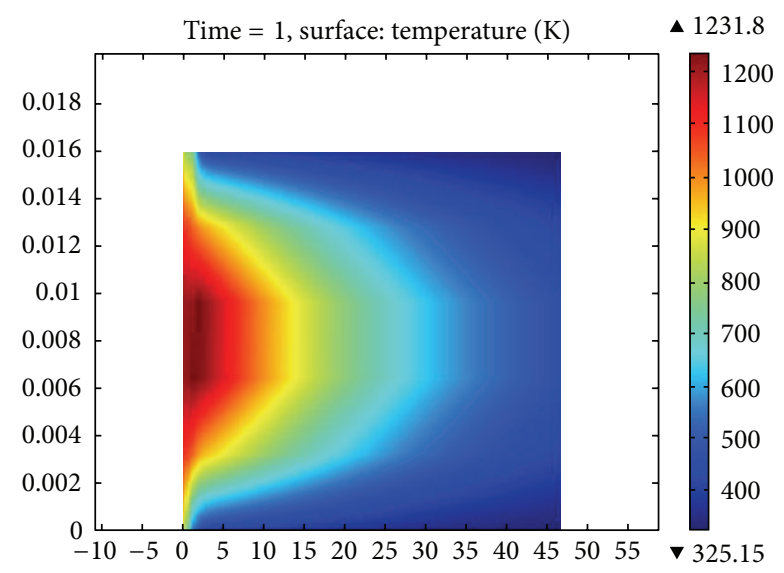

FIGURE 4: Temperature of strip using conjugate gradients method.

From simulation results, we found that the minimum percent relative error of surface temperature at cooling process at ROT is indicated by the case study number 1 and 2 . The largest percent true relative error is in the case study number 11 and 12. The output of strip temperature from simulation program on case study number 1 by using Comsol Multiphysics software is illustrated in Figures 3 and 4.

\section{Conclusions}

This research aims to study the effective cooling parameters at ROT of strip steel in hot rolling process. The desired quality of product must be achieved. In cooling process, the efficiency at ROT must be optimal to the customer requirement of strip steel grade. To find the optimal operating variables of ROT's cooling process, we develop the 2-dimensional transient heat transfer of strip steel developed by using mathematical model. Boundary and initial condition are bounded valuable by considering the practical conditions. Numerical solution is applied to solve the mathematical model built using a Comsol Multiphysics software by heat transfer module. Backward difference formula (BDF) applies to discretization of partial differentiation equation (PDE). The parallel sparse direct linear solver (PARDISO) and conjugate gradients method are comparisons for computation of linear algebraic equation. There are three variables useful for each simulation of case studies such as strip velocity, external fluid velocity, and temperature of cooling water, respectively. From the simulation results, the minimum percent relative error of strip surface temperature compared to strip temperature from finishing stand is the case study number 1 as depicted in Table 2 . The most suitability in operating control variables of ROT cooling system is achieved subject to industrial conditions of strip steel in hot rolling. Finally, the result has showed that the parallel sparse direct linear solver (PARDISO) is more proper than conjugate gradients method for linear algebra computation method.

\section{Acknowledgments}

The work described in this paper was partially supported by the Danieli Far East Co. LTD, Thailand, and Science and Technology Research Institute (STRI), KMUTNB, Thailand.

\section{References}

[1] A. Suebsomran and S. Butdee, "Cooling process on run out table by simulation method," Case Studies in Thermal Engineering, 2013.

[2] A. Mukhopadhyay and S. Sikdar, "Implementation of an on-line run-out table model in a hot strip mill," Journal of Materials Processing Technology, vol. 169, no. 2, pp. 164-172, 2005.

[3] C. G. Sun, H. N. Han, J. K. Lee, Y. S. Jin, and S. M. Hwang, "A finite element model for the prediction of thermal and metallurgical behavior of strip on run-out-table in hot rolling," ISIJ International, vol. 42, no. 4, pp. 392-400, 2002.

[4] S. Serajzadeh, "Prediction of temperature distribution and phase transformation on the run-out table in the process of hot strip rolling," Applied Mathematical Modelling, vol. 27, no. 11, pp. 861-875, 2003.

[5] S. Serajzadeh, "Prediction of temperature variations and kinetics of austenite phase change on the run-out table," Materials Science and Engineering A, vol. 421, no. 1-2, pp. 260-267, 2006.

[6] S. Serajzadeh, "Modelling of temperature history and phase transformations during cooling of steel," Journal of Materials Processing Technology, vol. 146, no. 3, pp. 311-317, 2004.

[7] H. N. Han, J. K. Lee, H. J. Kim, and Y.-S. Jin, "A model for deformation, temperature and phase transformation behavior of steels on run-out table in hot strip mill," Journal of Materials Processing Technology, vol. 128, no. 1-3, pp. 216-225, 2002.

[8] S. Edalatpour, A. Saboonchi, and S. Hassanpour, "Effect of phase transformation latent heat on prediction accuracy of strip laminar cooling," Journal of Materials Processing Technology, vol. 211, no. 11, pp. 1776-1782, 2011.

[9] X. Wang, Q. Yang, and A. He, "Calculation of thermal stress affecting strip flatness change during run-out table cooling in hot steel strip rolling," Journal of Materials Processing Technology, vol. 207, no. 1-3, pp. 130-146, 2008.

[10] J. Horsky, M. Raudensky, and P. Kotrbacek, "Experimental study of long product cooling in hot rolling," Journal of Materials Processing Technology, vol. 80-81, pp. 337-340, 1998. 
[11] H. Leocadio, J. Cesar Passos, and A. F. C. da Silva, "Heat transfer behavior of a high temperature stell plate cooled by a subcooled impringing circular water jet," in Proceedings of the 7th ECI International Conference on Boiling Heat Transfer, Florianópolis, Brazil, May 2009.

[12] S. C. Chapra and R. P. Canale, Numerical Methods for Engineers with Programming and Software Applications, McGraw-Hill, 2009.

[13] S. V. Patankar, Numerical Heat Transfer and Fluid Flow, Taylor and Francis, 1980.

[14] COMSOL Multiphysics User's Guide, VerSion 4. 1 1998-2010, COMSOL AB.

[15] COMSOL Multiphysics Reference Guide, Version 4. 1 1998-2010, COMSOL AB. 

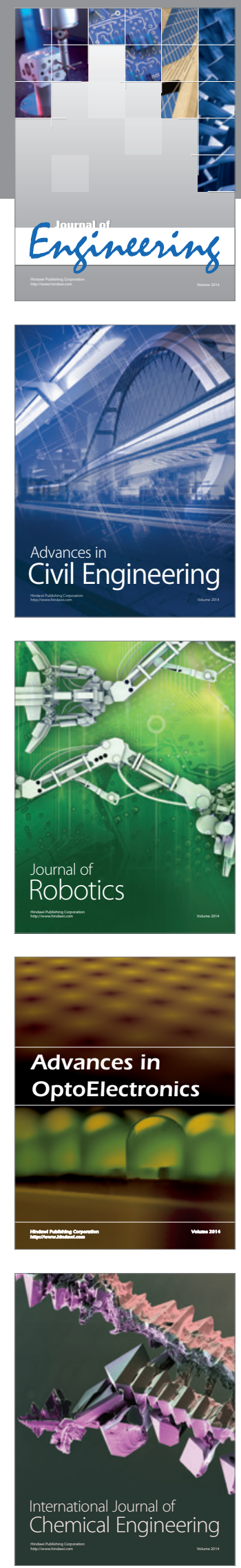

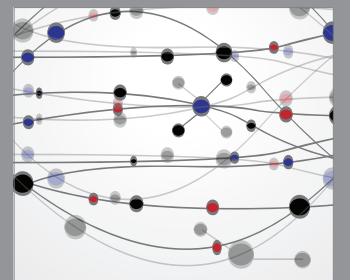

The Scientific World Journal
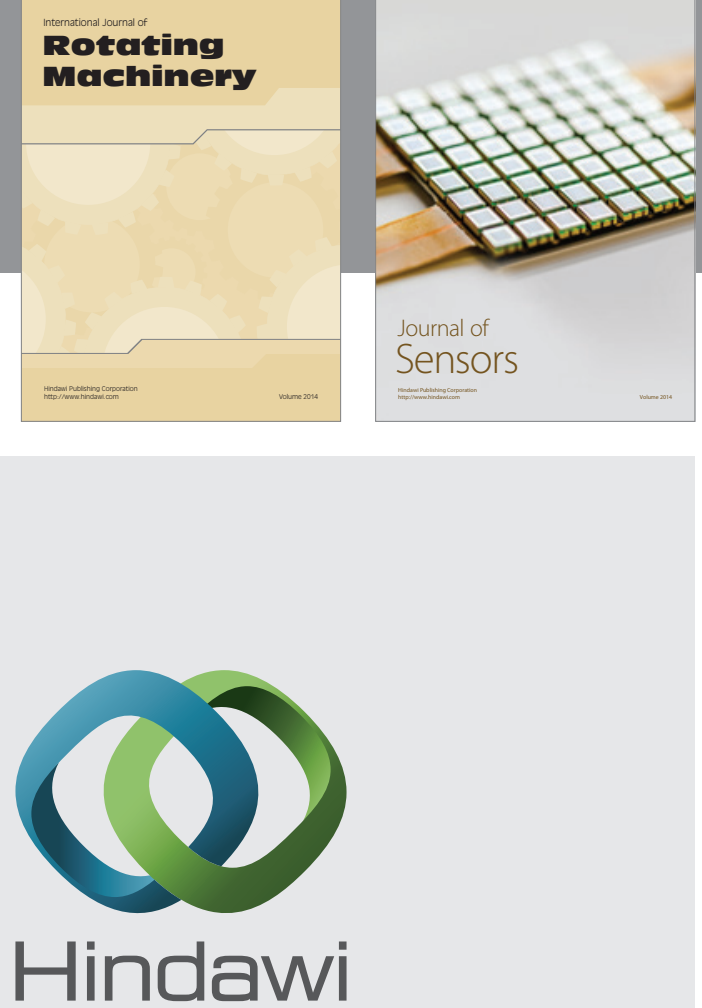

Submit your manuscripts at http://www.hindawi.com
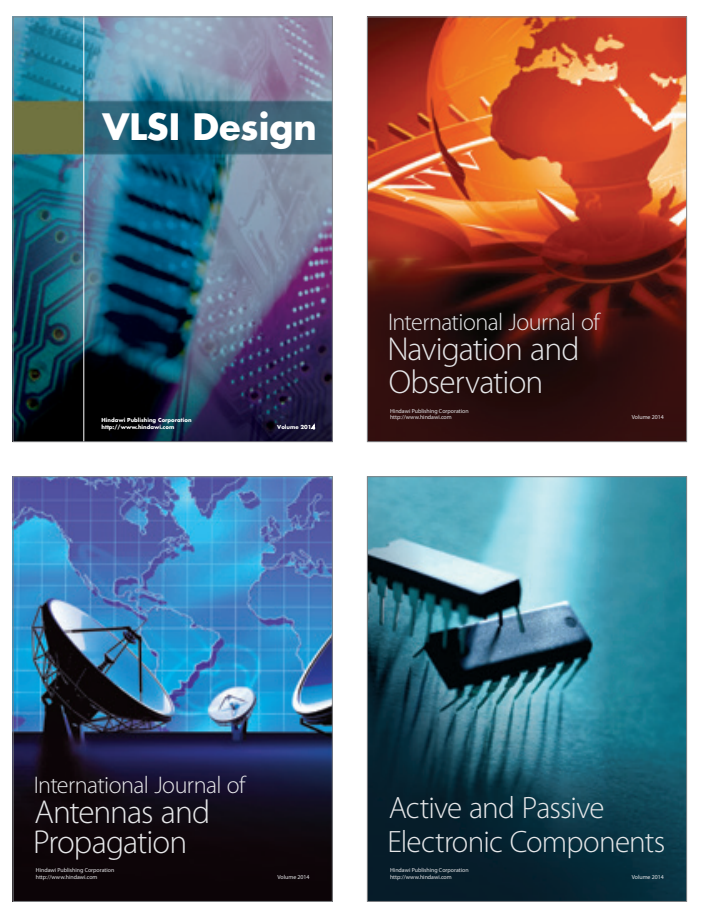
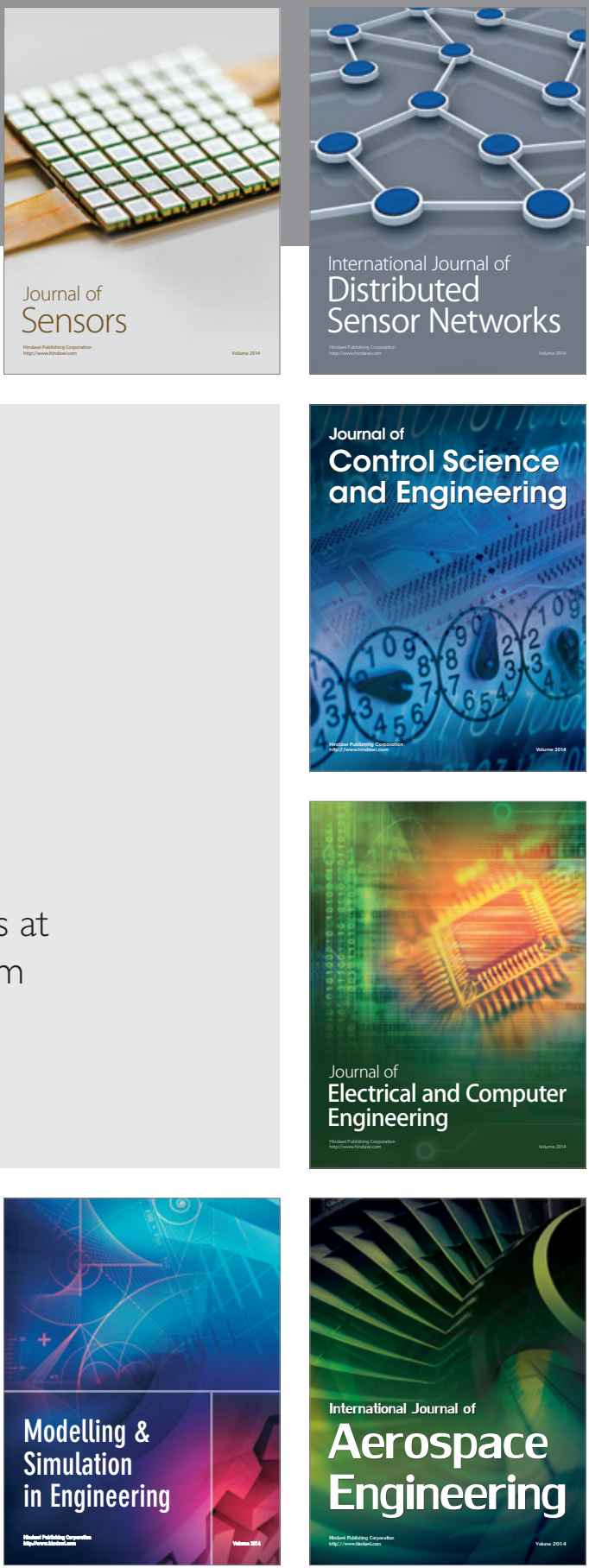

Journal of

Control Science

and Engineering
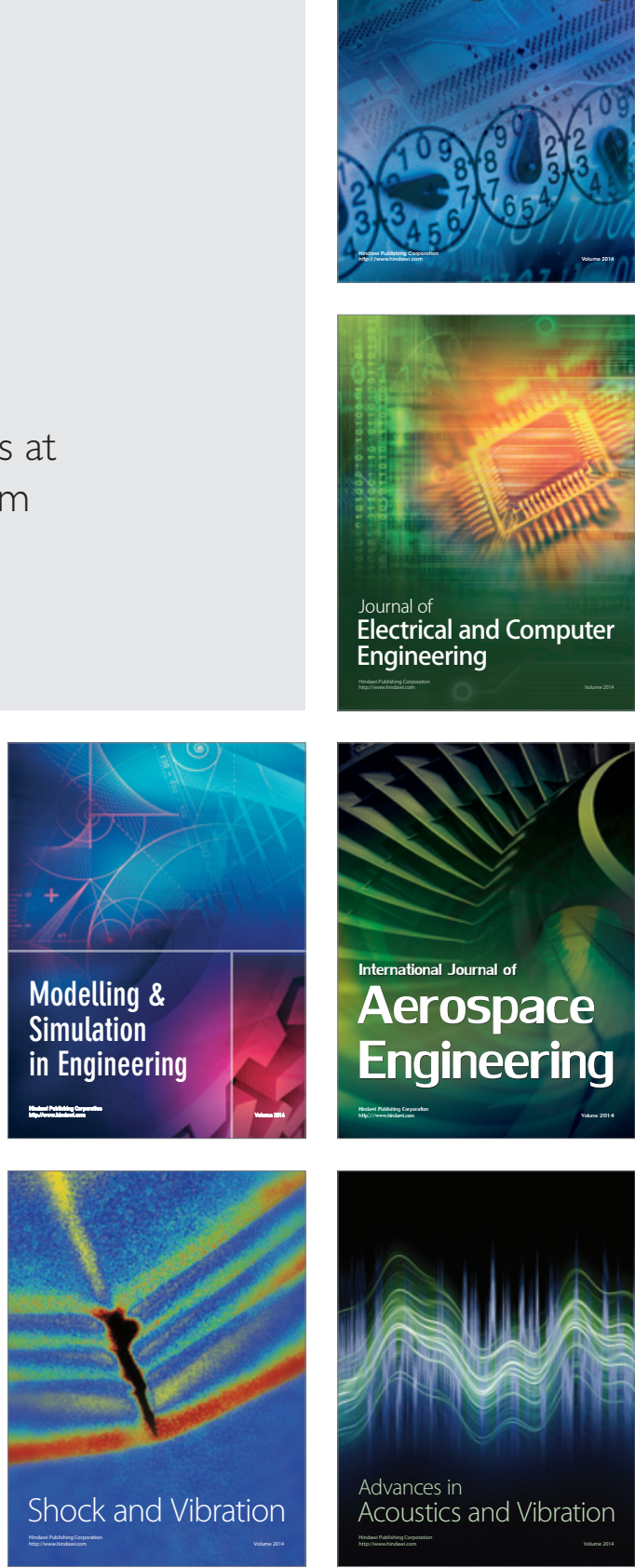